\title{
PROFILE OF HISTORY OF FEBRILE SEIZURE IN PATIENTS WITH EPILEPSY
}

\author{
Rayhan Muhammad Basyarahil ${ }^{1}$, Wardah Rahmatul Islamiyah ${ }^{2}$, Prastiya Indra Gunawan ${ }^{3}$ \\ Correspondence: basyarahilrayhan@gmail.com \\ ${ }^{I}$ Faculty of Medicine, Universitas Airlangga, Surabaya, Indonesia. \\ ${ }^{2}$ Department of Neurology, Faculty of Medicine, Universitas Airlangga, Surabaya, Indonesia \\ ${ }^{3}$ Department of Child Health, Faculty of Medicine, Universitas Airlangga, Surabaya, Indonesia
}

\section{Article History:}

Received: April 28, 2021

Accepted: Desember 13, 2021

Published: January 1, 2022

\section{Cite this as:}

Basyarahil RM, Islamiyah WR, Gunawan PI. Profile of history of febrile seizure in patients with epilepsy. Malang Neurology Malang Neurology Journal; 2022.8:21-24. DOI:

http://dx.doi.org/10.21776/ub.mnj .2022 .008 .01 .5

\section{ABSTRACT}

Background: Febrile seizure is convulsions with fever (temperature $\geq 38^{\circ} \mathrm{C}$ ) with no central nervous system infection that commonly found in children (6-60 months). Febrile seizures do not always mean the child has epilepsy. However, febrile seizures can be a possible long-term risk factor for epilepsy. Objective: The objective of this study is to know the profile of febrile seizure in patients with epilepsy.

Methods: A retrospective descriptive study on 23 patients with epilepsy in the EEG Department of Neurology, Dr. Soetomo General Hospital, Surabaya, Indonesia in the period 2018-2019 based on inclusion and exclusion criteria. The total number of epilepsy patients is 849 patients, 216 of whom had a history of febrile seizure. Among 216 epilepsy patients who had a history of febrile seizures, 23 of them were qualified as the sample. The sampling technique used was total population sampling. The instrument of this research is the patients' medical record. Data analysis is carried out descriptively.

Results: The characteristics of the history of febrile seizures that found in patients with epilepsy are more patients are male, have the age of onset on less than 2 years old, have the body temperature more than $38.3^{\circ} \mathrm{C}$, have the seizure duration less than 15 minutes, have focal seizures, have recurrent seizures in 24 hours, have a history of more than one febrile seizure, have accompanying neurological disorders, and have no family history of epilepsy.

Conclusion: Febrile seizure is still becoming a concern because there is a possibility that it may develop into epilepsy. Even though, not all children who experience febrile seizure will generate epilepsy.

Keywords: Febrile seizure, epilepsy

\section{Introduction}

Febrile seizure is convulsions with fever (temperature $\geq 38^{\circ} \mathrm{C}$ ) and with central nervous system infection that commonly found in children (6-60 months). The incidence of febrile seizures is about $5 \%$. It is said that febrile seizure is the most common type of seizure in children. ${ }^{1}$ In febrile seizures, there are no intracranial infections or other causes. $^{2}$ Febrile seizure was also said to be the most common neurological disorder. ${ }^{3}$ In the population of children under 5 years old, it is said that $3 \%$ of them have had a febrile seizure. ${ }^{4}$ Studies have shown that the prevalence of febrile seizures in Asia is twice that of America and Europe. ${ }^{5}$

Febrile seizure can be a concern for parents. Many parents of patients with febrile seizures worry that their child's febrile seizure is epilepsy or one day it will develop into epilepsy. In fact, febrile seizures do not always mean the child has epilepsy. ${ }^{6}$ However, febrile seizures can be a possible long-term risk factor for epilepsy. Previous retrospective studies, neuroimaging studies, and studies on animal experiments shows that some febrile seizures can generate epilepsy. ${ }^{7}$

One of the studies on a history of febrile seizures that progressed to epilepsy was conducted in Korea. From this study, it is known that $10 \%$ of patients who had previous febrile seizures were subsequently diagnosed with epilepsy. The risk factors of subsequent epilepsy are developmental disorders, preterm birth, multiple attacks in febrile seizures, and epileptiform discharge on electroencephalography. ${ }^{8}$ Another study that was conducted in January 2007 December 2010 at Sanglah General Hospital, Bali, found 276 cases of epilepsy, with an incidence of 5,3\%. Most of them grew normally $(75 \%)$, had previous febrile seizures $(10,1 \%)$, and had a family history with epilepsy $(13 \%) .{ }^{9}$

Several characteristics of febrile seizures are said to be risk factors for epilepsy, such as complex febrile seizure, age of onset of febrile seizure, febrile seizure with longer duration, high fever. In addition, a family history of epilepsy and neurodevelopmental abnormalities are also considered as risk factors for developing epilepsy. ${ }^{10}$ This study aims to know the profile of febrile seizure in patients with epilepsy. 


\section{Methods}

This retrospective descriptive study was conducted at Dr. Soetomo General Hospital, Surabaya, Indonesia. The study population was epilepsy patients in the EEG Department of Neurology Dr. Soetomo General Hospital. This study has obtained ethical eligibility from the Health Research Ethics Committee of Dr. Soetomo General Hospital. The sample of this study was all epilepsy patients in the EEG Department of Neurology, RSUD Dr. Soetomo in 20182019 based on inclusion and exclusion criteria. The inclusion criteria includes patients aged 5 to 40 years. The exclusion criteria is patients with incomplete medical record data consisting of history of febrile seizure, body temperature during febrile seizure, febrile seizure duration, type of seizure, frequency of seizures in 24 hours, number of history of febrile seizures, neurological disorders, and family history with epilepsy. The sampling technique used was total population sampling.

The study instrument is the patients' medical record. The data taken includes the number of history of febrile seizures, gender, age of onset of febrile seizure, body temperature during febrile seizure, duration of febrile seizure, type of seizure, frequency of seizures in 24 hours, number of history of febrile seizures, neurological disorders, and family history with epilepsy. The collected data will be processed by entry, coding, and cleaning and data analysis is carried out descriptively.

\section{Results}

The number of epilepsy patients in EEG Department of Neurology in Dr. Soetomo General Hospital was 849 patients, $216(24,2 \%)$ of whom had a history of febrile seizure. However, sample selection based on inclusion and exclusion criteria narrowed the sample to 23 patients. The research results are shown in the Table 1.

\section{Discussion}

The purpose of this research is to know the profile of history of febrile seizure in patients with epilepsy. This research is a retrospective descriptive study with a total sampling technique. This study found that males, age of onset less than 2 years old, body temperature more than $38.3^{\circ} \mathrm{C}$, seizure duration less than 15 minutes, focal seizure, recurrent seizure in 24 hours, history more than one febrile seizure, had accompanying neurological disorder, and no family history with epilepsy are the characteristic of the profile of history of febrile seizure in epilepsy patients.

Despite the limited research and literature, especially in the context of Indonesia, this research supports several previous studies and also contributes to the identification of patient characteristics in eastern Indonesia. The following are the details of the findings.

\section{Gender}

The distribution of epilepsy patient with a history of febrile seizure shows that more patients are male. This result was supported by the previous study which found $52 \%$ patients are male. ${ }^{8}$ Previous study shows an increased risk of febrile seizures in male patients, but the sex difference does not appear to be related to the prognostic factors of febrile seizure. The underlying explanation for the high risk of

Table 1. Characteristics of history of febrile seizure in patients with epilepsy.

\begin{tabular}{|c|c|c|}
\hline Variable & $\mathbf{n}=\mathbf{2 3}$ & Percent $(\%)$ \\
\hline \multicolumn{3}{|l|}{ Gender } \\
\hline Male & 19 & 82,61 \\
\hline Female & 4 & 17,39 \\
\hline \multicolumn{3}{|l|}{ Age of onset of febrile seizure } \\
\hline$<1$ years old & 6 & 26,09 \\
\hline $1-<2$ years old & 9 & 39,13 \\
\hline $2-<3$ years old & 2 & 8,69 \\
\hline $3-<4$ years old & 0 & 0 \\
\hline $4-<5$ years old & 6 & 26,09 \\
\hline \multicolumn{3}{|l|}{$\begin{array}{l}\text { Body temperature during } \\
\text { febrile seizure }\end{array}$} \\
\hline$<38,3^{\circ} \mathrm{C}$ & 5 & 21,74 \\
\hline$\geq 38,3^{\circ} \mathrm{C}$ & 18 & 78,26 \\
\hline \multicolumn{3}{|l|}{ Duration of febrile seizure } \\
\hline$<15$ minutes & 22 & 95,65 \\
\hline$\geq 15$ minutes & 1 & 4,35 \\
\hline \multicolumn{3}{|l|}{ Type of seizure } \\
\hline Focal onset & 3 & 13,04 \\
\hline General onset & 2 & 8,70 \\
\hline Unknown onset & 18 & 78,26 \\
\hline \multicolumn{3}{|l|}{$\begin{array}{l}\text { Frequency of seizures in } 24 \\
\text { hours }\end{array}$} \\
\hline Recurrent & 18 & 78,26 \\
\hline Nonrecurrent & 5 & 21,74 \\
\hline \multicolumn{3}{|l|}{$\begin{array}{l}\text { Number of history of febrile } \\
\text { seizures }\end{array}$} \\
\hline 1 & 5 & 21,74 \\
\hline$>1$ & 18 & 78,26 \\
\hline \multicolumn{3}{|l|}{ Neurological disorders } \\
\hline Motor impairment & 10 & 43,48 \\
\hline Mental disorder & 0 & 0 \\
\hline $\begin{array}{l}\text { Motor impairment and speech } \\
\text { disorder }\end{array}$ & 1 & 4,35 \\
\hline $\begin{array}{l}\text { Motor impairment and } \\
\text { developmental disorder }\end{array}$ & 1 & 4,35 \\
\hline Developmental disorder & 1 & 4,35 \\
\hline No neurological disorder & 10 & 43,48 \\
\hline \multicolumn{3}{|l|}{ Family history of epilepsy } \\
\hline Yes & 4 & 17,39 \\
\hline No & 19 & 82,61 \\
\hline
\end{tabular}

febrile seizures in males may be related to the high underlying susceptibility of males to seizure. Boys are more susceptible to respiratory tract infection (RTIs). In children, it is said that RTIs are the most common cause of fever. ${ }^{11}$

\section{Age of Onset of Febrile Seizure}

As for the age of onset, the study found that most patients experienced their first febrile seizure at the age of $1-<2$ years. This is consistent with the results of prior study, which showed the mean age of onset of febrile seizure in epilepsy patients was $26,3 \pm 22,9$ months or approximately 1-2 years old. Meanwhile, the mean age of onset in patients with febrile seizures who did not develop epilepsy was 21,3-12,5 months or approximately 1-2 years. Based on this study, the difference of age of onset in patients with subsequent epilepsy compared to febrile seizures patients who were not diagnosed with epilepsy did not show a significant difference. ${ }^{8}$ This may underlie the findings of this study. However, another study found that paroxysmal EEG abnormalities between 3-4 years old in febrile seizure 
patients might become a risk factor for subsequent epilepsy. ${ }^{12}$ Therefore, further investigations are needed.

\section{Body Temperature during Febrile Seizure}

This study found most of the patients had febrile seizure with body temperature $\geq 38,3^{\circ} \mathrm{C}$. These result show that there is a slight resemblance with the previous study. Based on the previous study, it was found that $56 \%$ patients with epilepsy with a history of febrile seizure had body temperature less than $39^{\circ} \mathrm{C}$. A possible explanation is that hyperthermia aggravates neuronal damage in humans with several types of brain injury including brain ischemia. ${ }^{13}$

\section{Duration of Febrile Seizure}

In this study, it was found that most of the patients experienced febrile seizure less than 15 minutes. This result is similar to a previous study that shows $72 \%$ of patient with febrile seizure and subsequent epilepsy had a seizure duration for about 30 seconds-15 minutes. However, the study showed no significant relation between subsequent epilepsy and febrile seizure duration. ${ }^{8}$

Even so, several study actually found that febrile seizure of long duration can increase the risk of epilepsy. ${ }^{14,15}$ Febrile seizures with longer duration may cause damage of developing brain structure and thus generate epilepsy. Prolonged febrile seizure also causes oedema of the hippocampus. ${ }^{7}$

A possible explanation related to the results of this study is that there were no significant distinction among the duration of the febrile seizure population and the febrile seizure population with subsequent epilepsy. So the population with subsequent epilepsy shows the same representation as the general febrile seizure population.

\section{Type of Seizure}

As for the type of seizure, this study found most types of seizure in patients were not classified. However, among the identified seizure types, it was found that more patients have focal seizures. Another study shows that the patient with complex febrile seizure (prolonged seizure, focal seizure, and repetitive seizure) had a significantly high risk for subsequent epilepsy. ${ }^{12}$ It is said that focal seizure is often related with developing temporal lobe epilepsy. ${ }^{13,16}$

Nonetheless, studies on focal semiology are still limited because it is relied on history taking from parents. The findings of this study are most likely related to dependence of the determination of the type of seizure based on history taking. Parents with anxiety are thought to be unable to clearly remember the exact form of the focal and seizure. ${ }^{8}$

\section{Frequency of Seizures in 24 Hours}

This study found more patients have recurrent seizures within 24 hours. In a previous study, from 25 epilepsy patients with a history of febrile seizures, 18 (72\%) of whom had recurrent seizures in one episode. ${ }^{8}$ This is suitable with the result of this study. The relationship between the incidence of multiple episodes of febrile seizure and an increased risk of epilepsy is not clear. One of the possible reason is that multiple episodes of febrile seizures may be an indicator of vulnerability to seizures. In addition, it is said that with each new seizure episode, an electrical balance disturbance occurs and can trigger further seizures. ${ }^{12}$

\section{Number of History of Febrile Seizures}

The distribution of the sample based on the number of history of febrile seizures showed that more patients have previous history of febrile seizures more than once. A retrospective study in China shows that recurrent febrile seizures can increase the epilepsy cumulative incidence. ${ }^{17}$

This supports the research data obtained that more patients had febrile seizures more than once. Another study conducted in Denmark also showed an increased risk of subsequent epilepsy in relation to the number of history of febrile seizures. Recurrent or multiple febrile seizures are often associated to longer seizure duration and higher severity. Therefore, it increases the chances of damaging the neurons. ${ }^{11}$

\section{Neurological Disorders}

In terms of neurological disorders, this study found more patients have concomitant neurological disorders. The most common neurological disorder is motor impairment. Several other neurological disorders were also found, such as speech disorder and developmental disorder. Some patients also have multiple overlapping neurological disorders. Previous study shows children with accompanying neurological disorders have a risk of epilepsy 26-30 times higher than normal children. ${ }^{14}$

This result is also supported by a study in Medan, Sumatra, that shows there is a significant relationship between neurological/growth and development disorders with the incidence of epilepsy in patients with previous febrile seizure. Patients who have neurological/growth and development disorders is 4,02 times more at risk of suffering from epilepsy. Epileptogenic processes during development are likely to depend on excessive neuron function rather than neurons that are dead. Then it is said that in temporal lobe type epilepsy with previous febrile seizures, cell loss (mesial temporal sclerosis/MTS) is often found to trigger epilepsy. ${ }^{18}$

Other studies have also shown that several developmental factors, such as congenital brain malformations and postnatal defects in neuronal network maturation, contribute to epilepsy. This may be related to the relationship between developmental disorders and the occurrence of epilepsy. ${ }^{19}$

\section{Family History of Epilepsy}

This study shows more patients do not have a history of epilepsy in their families. This is supported by a study in Korea that shows epilepsy patients with a previous febrile seizures history and a family history with epilepsy are as many as 2 patients out of $25(8 \%)$. Meanwhile, the other $92 \%$ did not have a family history with epilepsy. Even so, the study stated that family history with epilepsy had no relationship with subsequent epilepsy. ${ }^{8}$

However, another study also stated that family history of epilepsy was related with risk of generating epilepsy after febrile seizures. ${ }^{10}$ Another study in Denmark, showed the rate ratio for the incidence of epilepsy in patients with a history of febrile seizures and a family history of epilepsy was 12,7 , while the rate ratio for the incidence of epilepsy in patients with previous febrile seizures history and no family history of epilepsy was $5,6 .^{7}$ From these data, it can 
be seen that patients with a family history of epilepsy have a higher incidence of epilepsy.

These result variation can be caused by a wide genetic variation. Genetic analysis of familial epilepsy shows mutations in ion channel genes that produce multiple outcomes ranging from febrile seizures to severe epilepsy. ${ }^{7}$

\section{Conclusion}

Febrile seizure is still becoming a concern because there is a possibility that it may develop into epilepsy. Even though, not all children who experience febrile seizure will generate epilepsy later in life. This study concluded that the profile of history of febrile seizures in epilepsy patients occurred more in males, age of onset was less than 2 years old, body temperature was more than $38,3^{\circ} \mathrm{C}$, seizure duration was less than 15 minutes, focal seizures, recurrent seizures in 24 hours, had a history of more than one febrile seizure, had accompanying neurological disorders, and had no family history of epilepsy. Nevertheless, some of the patients' data were not extracted because the patient's family was less aware of the child's condition during febrile seizure, especially body temperature during febrile seizure. This study is expected to provide information about the profile of the history of febrile seizures in patients with epilepsy which can be applied and useful for the development of knowledge related to subsequent epilepsy after the occurrence of febrile seizures.

\section{Conflict of Interest}

The authors declare that there is no conflict of interest

\section{Acknowledgement}

The authors would like to thank Department of Neurology, Faculty of Medicine, Universitas Airlangga and Dr. Soetomo General Hospital for facilitating and supporting this study.

\section{References}

1. AAP. Febrile seizures: Guideline for the neurodiagnostic evaluation of the child with a simple febrile seizure. Pediatrics; 2011. 127(2):389-394. DOI: $10.1542 /$ peds.2010-3318

2. Leung AKC, Hon KL, Leung TNH. Febrile seizures: An overview. Drugs in Context; 2018. 7:212536. DOI: $10.7573 /$ dic. 212536

3. Dewanti A, Widjaja JA, Tjandrajani A, Burhany AA. Kejang demam dan faktor yang mempengaruhi rekurensi. Sari Pediatri; 2012. 14(1):57-61. DOI: $10.14238 / \mathrm{sp} 14.1 .2012 .57-61$

4. Delpisheh A, Veisani Y, Sayehmiri K, Fayyazi A. Febrile seizures: etiology, prevalence, and geographical variation. Iran J Child Neurol; 2014. Summer;8(3):30-7. PMID: 25143771; PMCID: PMC4135278.

5. Fuadi F, Bahtera T, Wijayahadi N. Faktor risiko bangkitan kejang demam pada anak. Sari Pediatri; 2010. 12(3). DOI: 10.14238/sp12.3.2010.142-9
6. NINDS. Febrile seizures fact sheet. 2020. Retrieved on April 26 2021. Available from: https://www.ninds.nih.gov/Disorders/PatientCaregiver-Education/Fact-Sheets/Febrile-SeizuresFact-Sheet

7. Vestergaard M, Pedersen C, Sidenius P, Olsen J, Christensen J. The long- term risk of epilepsy after febrile seizures in susceptible subgroups. American Journal of Epidemiology; 2007. 165(8):911-918. DOI: $10.1093 / \mathrm{aje} / \mathrm{kwk} 086$

8. Lee SH, Byeon JH, Kim GH, Eun BL, Eun SH. Epilepsy in children with a history of febrile seizures. Korean J Pediatr; 2016. 59(2):74-79. DOI: $10.3345 / \mathrm{kjp} .2016 .59 .2 .74$

9. Suwarba, IGNM. Insidens dan karakteristik klinis epilepsi pada anak. Sari Pediatri; 2011. 13(2):123-128. DOI: $10.14238 / \mathrm{sp} 13.2 .2011 .123-8$

10. Chung S. Febrile seizure. Korean J Pediatr; 2014. 57(9):389-395. DOI: 10.3345/kjp.2014.57.9.384

11. Dreier JW, Li J, Sun Y, Christensen J. Evaluation of long-term risk of epilepsy, psychiatric disorders, and mortality among children with recurrent febrile seizures: a national cohort study in Denmark. JAMA Pediatrics; 2019. 173(12):1164-1170.

DOI: 10.1001/jamapediatrics.2019.3343

12. Kanemura H, Mizorogi S, Aoyagi K, Sugita K, Aihara M. EEG characteristics predict subsequent epilepsy in children with febrile seizure. Brain and Development; 2012. 34(4):302-307. DOI: 10.1016/j.braindev.2011.07.007

13. Nishiyama $M$, Nagase $H$, Tanaka $T$, Fujita $K$, Maruyama A, Toyoshima D, Nakagawa T, TaniguchiIkeda M, Morioka I, Morisada N, Takada S, Iijima K. Demographics and outcomes of patients with pediatric febrile convulsive status epilepticus. Pediatr Neurol; 2015. 52(5):499-503.

DOI: $10.1016 /$ j.pediatrneurol.2015.02.001

14. Hasibuan DK, Dimyati Y. Kejang demam sebagai faktor predisposisi epilepsi pada anak. Cermin Dunia Kedokteran-290; 2020. 47(9).

15. Pavlidou E, Panteliadis C. Prognostic factors for subsequent epilepsy in children with febrile seizures. Epilepsia; 2013. 54(12). DOI: 10.1111/epi.12429

16. Patterson KP, Baram TZ, Shinnar S. Origins of temporal lobe epilepsy: febrile seizures and febrile status epilepticus. Neurotherapeutics; 2014. 11:242250. DOI: $10.1007 / \mathrm{s} 13311-014-0263-4$

17. Tsai JD, Mou CH, Chang HY, Li TC, Tsai HJ, Wei CC. Trend of subsequent epilepsy in children with recurrent febrile seizures: A retrospective matched cohort study. Seizure; 2018. 61:164-169.

DOI: 10.1016/j.seizure.2018.08.019

18. Hasibuan DK. Faktor-faktor yang berperan dalam kejadian epilepsi pada anak dengan riwayat kejang demam [thesis on the internet]. Medan, Universitas Sumatera Utara; 2020. Retrieved on April 262021. Available from: http://repositori.usu.ac.id/handle/123456789/29099

19. Bozzi Y, Casarosa S, Caleo M. Epilepsy as a neurodevelopmental disorder. Frontiers in psychiatry; 2012. 3(19). DOI: 10.3389/fpsyt.2012.00019 